\title{
Elaboración de Queso de Capa a partir de Leche de Búfala del Municipio Carmen de Bolívar (Colombia)
}

\section{Clemente Granados*, Liz A. Meza, Raquel S. Paba y Diofanor Acevedo}

Universidad de Cartagena, Facultad de Ingeniería, Departamento de ingeniería de Alimentos, Avenida el Consulado, Calle 30 No. 48-152. Cartagena, Bolívar-Colombia (e-mail: clementecondeg@gmail.com)

${ }^{*}$ Autor a quien debe ser dirigida la correspondencia

Recibido Mar. 11, 2014; Aceptado Abr. 30, 2014; Versión final recibida May. 21, 2014

\section{Resumen}

Se describe el proceso de elaboración del queso de capa a partir de leche bufalina con 4,07\% (Queso 1) y $10,9 \%$ (Queso 2) de grasa. El queso de capa, es un queso de pasta hilada producido artesanalmente en Santa Cruz de Mompox en Colombia. Se realizaron pruebas fisicoquímicas y microbiológicas a la materia prima y al producto final. Este último también se caracterizó texturalmente y se le calculó su rendimiento. La leche cruda de búfala y queso de capa elaborado presentaron los requisitos de calidad permitidos por la normativa colombiana. El queso de capa 1 tuvo un rendimiento en masa del 10,93\%, mientras que el queso de capa 2 tuvo un rendimiento del 16,38\%. Estos resultados son de interés tecnológico, ya que pueden transferirse para su utilización por un organismo de control gubernamental o a empresas elaboradoras de este tipo de producto.

\section{Layer Cheese made from Buffalo Milk in The Municipality of Carmen de Bolívar (Colombia)}

\begin{abstract}
The process of capa cheese making described from buffalo milk with 4,07\% (Cheese 1) and 10,9\% (cheese 2) fat. Capa cheese is a spun paste cheese handmade produced in Santa Cruz de Mompox in Colombia. Physicochemical and microbiological analyses of the raw material and of the final were performed. The latter was also texturally characterized and its performance was determined. Raw buffalo milk and capa cheese presented the quality requirements established by Colombian standards. The capa cheese 1 had a mass yield of 10,93 weight \% while the cheese layer 2 had a mass yield of $16,38 \%$. These results are of technological interest because they can be transferred to be used by a government control agency or by enterprises producing this type of product.
\end{abstract}

Keywords: layer cheese, buffalo milk, physicochemical tests, microbiological tests, textural characterization 


\section{INTRODUCCIÓN}

Se define a la leche como el producto de la secreción de las glándulas mamarias de mamíferos, especialmente de ganado bovino y caprino. Hay otros animales utilizados en la adquisición de leche, e incluyen el búfalo, la oveja, el camello y la llama, no obstante su consumo es esporádico (Araya et al., 2008). La leche, aun cuando provenga de diversas especies, contiene, de manera general, los mismos constituyentes nutricionales, dándose variaciones muy ligeras en composición y propiedades. Los componentes que más varían son las proteínas y las grasas (Sbodio et al., 2010). La vaca constituye, por excelencia, el mayor productor de leche a nivel mundial, pero en los últimos años se ha dado un incremento importante en la producción e industrialización de leche de búfalo (Araya et al., 2008; Abdel-Azis et al., 2000).

La producción mundial de leche de búfalo estimada para el 2009 fue de 89 millones de toneladas, lo que representa un aumento promedio desde 1998 del 3,5\% anual y contribuye al $13 \%$ de la producción mundial, ocupando el segundo lugar después de la leche de vaca, la cual presenta una producción anual de 580 millones de toneladas (Simanca et al., 2013). Las características fisicoquímicas y organolépticas de la leche de búfalo facilitan su identificación: presenta un sabor peculiar, levemente endulzado y color blanco, debido a la ausencia casi total de carotenos en su grasa (Andrade et al., 2010). Cada vez es mayor el interés en investigaciones e inversión por la leche de búfalo en varios países, debido principalmente a su atractivo contenido de nutrientes. En comparación con la leche de vaca, la leche de búfalo tiene un mayor contenido de grasa, proteína cruda, lactosa, sólidos totales, vitaminas y minerales, que la convierten en un ingrediente adecuado para la fabricación de una amplia variedad de productos lácteos, tales como queso, mantequilla, helados y yogurt (Simanca et al., 2013; Ahmad et al., 2008; Andrade et al., 2010; Hussain et al., 2012).

El queso de capa es procedente del municipio de Santa Cruz de Mompox (Colombia), y es un producto artesanal que pertenece a la familia de los quesos de pasta hilada, donde la cuajada previamente acidificada, se somete a un amasado en caliente que permite plastificarla de tal forma que pueda formar bandas, a su vez constituidas por estructuras alineadas que se pueden separar como "hilos" (Granados et al., 2010). En estudios preliminares Granados et al., (2010) describieron el proceso de producción artesanal y de tecnificación, y realizaron análisis fisicoquímicos y microbiológicos del queso de capa de Santa Cruz de Mompox (Colombia). Maldonado y Llanca (2008) investigaron las características físico-químicas y microbiológicas de 32 muestras de queso de capa provenientes de cuatro centros de mayor venta en el municipio Girardot, Edo. Aragua (Venezuela). Los resultados obtenidos en el análisis físico-químico demostraron que entre cada lote y entre centros de ventas hay una variación bastante notable para cada variable evaluada, posiblemente debido a razones multifactoriales como falta de estandarización en el esquema tecnológico, manejo inadecuado en el transporte y almacenamiento, falta de controles en las condiciones de temperatura y tiempo de almacenamiento. Los resultados de la evaluación microbiológica demostraron que todas las muestras estudiadas están por encima de los valores recomendados por la norma Venezolana COVENIN. Por lo tanto, el consumo del queso de capa, en los centros evaluados, puede constituir un riesgo de salud pública. Por otro lado Lengua et al., (2010) evaluaron la calidad higiénica del queso de capa del municipio de Mompóx y la capacidad bactericida de Lactobacillus spp aislados de un producto comercial (yogurt). Este estudio arrojó que los recuentos microbiológicos sobrepasan los valores establecidos por la legislación colombiana. Lo anterior evidencian que los quesos de capa comercializados presentan ausencia de controles en las etapas de procesamiento, almacenamiento y comercialización, ausencia de adecuadas condiciones de higiene y manipulación de la leche a nivel de fincas y centros de producción de leche y del producto final a nivel de centros de procesamiento de la leche y fabricación del producto final, lo que haría tener en este tipo de queso, baja calidad fisicoquímica y microbiológica. Esto ocasiona un producto alimenticio, con corto tiempo de vida útil que no permite mantener sus características su calidad, lo que dificultad su comercialización a gran escala (Maldonado y Llanca, 2008). Otros autores han producidos quesos a partir de leche de búfalo, más específicamente quesos tradicionales italiana di Mozzarella Búfalo de Campana en Italia (Gianferri et al., 2007a; 2007b; Mazzei y Piccolo, 2012; Romano et al., 2011). Como alternativa para mejorar la calidad y comercialización, este trabajo propone elaborar, estandarizar y caracterizar el queso de capa a partir de leche de búfalo en el municipio del Carmen de Bolívar (Colombia).

\section{MATERIALES Y MÉTODOS}

\section{Caracterización fisicoquímica y microbiológica de la leche cruda y queso capa}

Se realizaron de acuerdo a Norma Técnica Colombiana (NTC) 399 (2002) a la leche, y al queso de capa de acuerdo a NTC 750 (2000). Para determinar la calidad microbiológica se realizó recuento total de bacterias aerobias mesófilas, coliformes totales y fecales, mohos y levaduras, Staphylococcus aureus coagulasa (+), Esporas de Clostridios sulfito reductores, Bacillus cereus y Salmonella spp. Los recuentos se expresaron en 
UFC/g. Las mediciones se realizaron por triplicado y fueron expresados en promedio con su respectiva desviación estándar. Los valores obtenidos de la caracterización fisicoquímica y microbiológica de la leche y queso se confrontaron con los requisitos establecidos en Decreto 616 (2006) y NTC 750 (2000) para leche y quesos respectivamente.

\section{Proceso de elaboración de queso de capa}

La elaboración del queso se realizó de acuerdo a metodología propuesta por Granados et al., (2010) en su trabajo de tecnificación, caracterización fisicoquímica y microbiológica del queso de capa de Santa Cruz de Mompox (Colombia). La leche cruda de búfalo se filtró, y luego se estandarizó al 4,07 y 10,9\% de grasa utilizando crema fresca al 10\%. Los procesos que vienen se realizaron a parte para cada tipo de leche con diferente porcentaje graso. Se realizó pasteurización lenta (65 ${ }^{\circ} \mathrm{C}$ durante 30 minutos). La leche pasteurizada se enfrió a $35{ }^{\circ} \mathrm{C}$, su $\mathrm{pH}$ se ajustó a un valor de 5,2 con la adición de suero ácido, posteriormente se adicionó cuajo MARSHALL M-50 (Fuerza 1:50), se agitó y se dejó en reposo durante 30 minutos hasta la separación final de la cuajada del suero, se verificó que el pH fuera de 5,2, se realizó el hilado utilizando parte del suero fresco previamente calentado a una temperatura de $60{ }^{\circ} \mathrm{C}$; se adicionó $2 \%$ de sal y extendió la masa hasta un espesor de 0,4 centímetros, donde fue cortada en láminas de 2,5 por 12 $\mathrm{cm}$. Posteriormente se enrolló la primera tira sobre sí misma, la segunda sobre la primera en el sentido transversal hasta obtener un peso final de 80 gramos y finalmente se empacó en bolsas de polietileno al vacío con peso aproximado de 80 gramos. El peso final del queso se tomó como la cantidad de masa extraída de la separación de la cuajada del suero dulce, sin la adición de cloruro de sodio. El rendimiento se expresó en porcentaje.

\section{Caracterización textural}

Se utilizó un texturómetro Marca Shimadzu y el software Rheometer. Se cortaron rodajas de queso de aproximadamente $1,5 \mathrm{~cm}$ de grosor y se dejaron reposar por una hora a temperatura ambiente dentro de una bolsa de polietileno para evitar la pérdida de humedad (Granados et al., 2013). El método fue realizado mediante la aplicación de una fuerza de compresión dos veces sucesivas en las muestras, con el fin de simular la masticación humana y calcular los parámetros estudiados: Máxima fuerza (N), Máxima tensión $\left(\mathrm{N} / \mathrm{m}^{2}\right)$, Máximo desplazamiento $(\mathrm{mm})$, Máxima deformación (\%) y Máximo tiempo (s).

\section{Diseño experimental}

En esta investigación, se estudiaron dos tratamientos: leche cruda de búfalo estandarizada a 4,07 y 10,9\% de grasa. De ahora en adelante los conoceremos como queso 1 y 2 respectivamente. De cada tipo de queso se obtuvieron 3 lotes, para poder realizar tres repeticiones, en un diseño experimental totalmente aleatorio. Las variables respuesta fueron: los análisis proximales, análisis microbiológicos y la caracterización textural, las cuales se expresaron como media con su respectiva desviación estándar. Se utilizó el programa StatgraphicsCenturion XVI.I. Para el análisis de los datos, se aplicó un análisis de varianza (ANOVA) y el análisis de medias, mediante un test de Tukey-Kramer; se fijó el nivel de significancia $a p<0,05$.

\section{RESULTADOS Y DISCUSIÓN}

\section{Análisis fisicoquímicos de la leche fresca de búfalo}

En la Tabla 1 se muestran los análisis fisicoquímicos que arrojó la leche fresca de búfalo. El Tiempo de reducción del azul de metileno (TRAM) indica que esta leche es de buena calidad microbiológica por el tiempo que duro en perder el color azul (Granados et al., 2010). La muestra no tiene ningún tipo de neutralizantes, y la acidez exhibió un valor de $0,18 \%$ que se encuentra entre los rangos encontrados por Granados et al., (2010). Pero supera ligeramente, el valor recomendado por el Ministerio De Protección Social en el Decreto 616 (2006), lo cual indica que esta es una leche que se puede utilizar para la elaboración leche pasteurizada y diferentes tipos de quesos, ya que se produce agregación de la caseína más fácilmente (Sbodio et al., 2010).

A diferencia de la leche vacuna, la bufalina consta de elevados contenidos de grasa (Simón y Galloso, 2011), tal como se puede observar en la Tabla 1. Aunque también hay que tener en cuenta que la alimentación, raza, edad, etapa de lactancia, método de ordeño y el ambiente son factores que afectan este valor (Simón y Galloso, 2011). El bajo índice crioscópico también se debe al alto contenido graso, ya que esta baja el punto de congelación de la leche (Badui, 2006), además a la ausencia de agua añadida a la leche. El pH, lactosa, proteínas y sales se encuentran dentro del rango característico de la leche de búfalo (Granados et al., 2010; Zuñiga et al., 2007). 
Tabla 1: Resultado de análisis fisicoquímicos de la leche fresca de búfalo

\begin{tabular}{|c|c|c|}
\hline Tipo de análisis & Resultados & Requisito leche bovina \\
\hline TRAM (Horas) & $4 \mp 0,0$ & $>3$ \\
\hline Neutralizantes (prueba de alizarina) & Negativo & Negativo \\
\hline Acidez (\% de acido láctico) & $0,18 \mp 0,01$ & $0,13-0,17$ \\
\hline Grasa (\%) & $10,09 \mp$ & 3 \\
\hline Lactosa (\%) & $4,87 \mp 0,04$ & $4-5$ \\
\hline Sólidos totales (\%) & $8,72 \mp 0,06$ & Mínimo 8,3 \\
\hline Proteínas (\%) & $3,19 \mp 0,03$ & Mínimo 2,9 \\
\hline Agua adicionada (\%) & $0 \mp 0,0$ & 0 \\
\hline Índice crioscópico $\left({ }^{\circ} \mathrm{C}\right)$ & $-0,62 \mp 0,04$ & $-0,53-0,51$ \\
\hline $\mathrm{pH}$ & $6,65 \mp 0,01$ & $6,5-6,8$ \\
\hline
\end{tabular}

Análisis microbiológico de la leche fresca

En general, de acuerdo a los resultados de la Tabla 2, la leche bufalina utilizada para elaborar queso de capa, es adecuada para el procesamiento de productos lácteos, ya que su contenido microbiológico está dentro de los rangos permitidos establecidos por el Decreto 616 del año 2006. Los recuentos se midieron en UFC/g. Otros autores obtuvieron los mismos resultados (Granados et al., 2010; Maldonado y Llanca, 2008).

Tabla 2: Análisis microbiológico de la leche fresca de búfalo

\begin{tabular}{|c|c|c|}
\hline Parámetros & Resultado & Requisito \\
\hline Aerobios mesófilos (UFC/g) & 10000 & $<50000$ \\
\hline Coliformes totales (UFC/g) & 20 & $<93$ \\
\hline Coliformes fecales (UFC/g) & $<3$ & $<3$ \\
\hline Mohos y levaduras (UFC/g) & $<100$ & $<200$ \\
\hline Staphylococcus aureus coagulasa (+) & $<100$ & 200 \\
\hline Esporas de Clostridios sulfito reductores & $<100$ & $<500$ \\
\hline Bacillus cereus & $<100$ & $<10^{4}$ \\
\hline Salmonella spp. & Negativa & Negativa \\
\hline
\end{tabular}

Análisis fisicoquímicos del queso de capa

En la Tabla 3 se muestran los análisis fisicoquímicos que se realizaron a los quesos capa 1 y 2 . Esta muestra que el queso 1 tuvo menor contenido graso y mayor contenido de cenizas que el queso $2(p<0,05)$. De acuerdo a la NTC 750 (2000) según su contenido graso el queso 1 se cataloga como descremado $(<10 \%)$, y el queso 2 como semidescremado (10-25\%); y según su contenido de humedad ambos quesos se clasifican como extraduros. Según González-Tenorio et al., (2013) entre mas alto sea el contenido de humedad del producto, menor será la cantidad de cenizas de este mismo, tal como se ve reflejado en los datos obtenidos en este estudio.

Tabla 3: Análisis fisicoquímico de quesos

\begin{tabular}{|c|c|c|c|}
\hline Análisis & Queso 1 & Queso 2 & Requisito \\
\hline Grasa (\%) & $6,75 \mp 0,35^{\mathrm{a}}$ & $22,75 \mp 1,06^{\mathrm{b}}$ & $0-25$ \\
\hline Humedad (\%) & $20,22 \mp 0,82^{\mathrm{a}}$ & $21,12 \overline{\mp 0,31^{\mathrm{a}}}$ & $<51$ \\
\hline Acidez (\% de acido láctico) & $0,22 \bar{\mp} 0,007^{\mathrm{a}}$ & $0,19 \mp 0,05^{\mathrm{a}}$ & $\mathrm{N} / \mathrm{A}$ \\
\hline Cenizas (\%) & $3,98 \mp 0,03^{\mathrm{b}}$ & $2,82 \bar{\mp} 0,02^{\mathrm{a}}$ & $\mathrm{N} / \mathrm{A}$ \\
\hline
\end{tabular}

\section{Análisis microbiológicos del queso de capa}

En la Tabla 4 se muestran los análisis microbiológicos a quesos de capa 1 y 2 , y se compara con el índice máximo permisible para identificar nivel de buena calidad según la NTC 750 (2000) que establece los requisitos microbiológicos que debe tener el queso fresco. Los recuentos microbiológicos de quesos se encuentran dentro de los rangos permitidos por la NTC 750 (2000), como se ve reflejado en la Tabla. Otros autores obtuvieron los mismos resultados (Granados et al., 2010; Maldonado y Llanca, 2008).

Tabla 4: Análisis microbiológico de quesos

\begin{tabular}{|c|c|c|c|c|c|}
\hline $\begin{array}{c}\text { Muestras de } \\
\text { queso }\end{array}$ & $\begin{array}{c}\text { Coliformes } \\
\text { Totales }\end{array}$ & $\begin{array}{c}\text { Coliformes fecales } \\
(\text { UFC/g) }\end{array}$ & $\begin{array}{c}\text { Staphilococcus } \\
\text { coagulasa }(+)\end{array}$ & $\begin{array}{c}\text { Mohos y } \\
\text { levaduras }\end{array}$ & $\begin{array}{c}\text { Salmonella } \\
\text { spp. }\end{array}$ \\
\hline Queso 1 & $<10$ & $<3$ & $<100$ & $<10$ & Negativo \\
\hline Queso 2 & $<10$ & $<3$ & $<100$ & $<10$ & Negativo \\
\hline Requisito & 1000 & 50 & 100 & 500 & Negativo \\
\hline
\end{tabular}




\section{Caracterización textural}

En la Tabla 5 se muestran los resultados de la caracterización textural a quesos de capa 1 y 2 , que se compararon con un queso capa tradicional elaborado a partir de leche de vaca. Para Zuñiga et al., (2007), las propiedades texturales del queso se ven afectadas por su composición fisicoquímica, siendo importantes el contenido de grasa, proteínas y humedad, aunque también influyen la tecnología de procesamiento y la intensidad de la proteólisis. Los valores de Máxima fuerza y Máxima tensión fueron mayores en los quesos 2 y tradicional $(p<0,05)$, mientras que el Máximo desplazamiento, la Máxima deformación y el Máximo tiempo fueron mayores para los quesos 1 y $2(p<0,05)$.

Debido a que la dureza es la Máxima fuerza obtenida durante el primer ciclo de compresión y que la leche de vaca a partir de la cual de elaboró el queso de capa tradicional presentan menor contenido graso, en la Tabla 5 se observa que la dureza aumenta a medida que la grasa disminuye. Esto concuerda con Zúñiga et al., (2007), quienes dicen, que un incremento en materia grasa y contenido de agua debilitan la estructura proteica, mientras que una disminución de los mismos provoca un endurecimiento en el queso. En la Tabla 5 podemos observar que el queso 1 presenta mayor deformación, lo cual es lógico, ya que entre menos duro este el queso, menor energía se requiere para masticarlo, esto debido a que la dureza y la cohesión aumentan en la misma proporción como lo explica Zuñiga et al., (2007).

Tabla 5: Caracterización textural de quesos

\begin{tabular}{|c|c|c|c|}
\hline Variable & Queso 1 & Queso 2 & Queso capa tradicional \\
\hline Máxima fuerza (N) & $11,35 \mp 1,52^{\mathrm{a}}$ & $22,39 \mp 1,52^{\mathrm{b}}$ & $22,42 \mp 1,61^{\mathrm{b}}$ \\
\hline Máxima tensión (N/m2) & $2,04 \mp 0,75^{\mathrm{a}}$ & $3,41 \mp 0,50^{\mathrm{b}}$ & $3,42 \mp 0,51^{\mathrm{b}}$ \\
\hline Máximo desplazamiento (mm) & $15,08 \mp 0,00^{\mathrm{a}}$ & $15,00 \mp 0,00^{\mathrm{a}}$ & $15,01 \mp 0,02^{\mathrm{b}}$ \\
\hline Máxima deformación (\%) & $502,83 \mp 0,07^{\mathrm{a}}$ & $500,04 \mp 0,01^{\mathrm{a}}$ & $500,18 \mp 0,18^{\mathrm{b}}$ \\
\hline Máximo tiempo (s) & $9,07 \mp 0,03^{\mathrm{a}}$ & $9,00 \mp 0,00^{\mathrm{a}}$ & $9,00 \mp 0,00^{\mathrm{b}}$ \\
\hline
\end{tabular}

\section{Rendimiento}

El rendimiento de la producción de queso depende directamente de una gran cantidad de factores de los cuales los más importantes son el porcentaje de grasa, la humedad del queso, el método de fabricación y cuidados adoptados en el corte (Simón y Galloso, 2011; Granados et al., 2010). El queso de capa que 1 tuvo un rendimiento en peso del 10,93\%, mientras que el queso de capa 2 tuvo un rendimiento del $16,38 \%$. Este mayor rendimiento a partir de leche de búfalo con mayor porcentaje graso era de esperarse, ya que según Acevedo et al., (2010) el porcentaje graso y materia seca está directamente relacionados con el rendimiento en la elaboración de quesos. La leche de búfalo, al igual que la de cabra y oveja, se utiliza casi exclusivamente para la elaboración de quesos en algunos países, debido especialmente al elevado rendimiento quesero y al alto contenido de sólidos (Simón y Galloso, 2011). Para aumentar el peso, y de igual manera incrementar el rendimiento del queso, se adicionó cloruro de calcio, que es aquel que acelera la coagulación, reduce la cantidad de cuajo necesario, y origina un gel mas firme (Sbodio et al., 2010). Sbodio et al., (2010), afirman que el cloruro de calcio facilita la coagulación, mejora el rendimiento, acelera de cierto modo la salida del suero y determina una mejor retención de grasa y otros sólidos.

\section{CONCLUSIONES}

Las caracterizaciones microbiológicas y fisicoquímicas de este estudio son de utilidad como base de parámetros característicos para la producción de queso de capa a partir de leche de búfalo. Estos resultados son de interés tecnológico, ya que pueden transferirse para su utilización por un organismo de control gubernamental o a empresas elaboradoras de este tipo de producto. Los recuentos microbiológicos de quesos se encuentran dentro de los rangos permitidos. El queso de capa 1 tuvo un rendimiento en peso del $10,93 \%$, mientras que el queso de capa 2 tuvo un rendimiento del $16,38 \%$.

\section{REFERENCIAS}

Abdel-Azis, M. y otros tres autores, Incidence and seasonal variation of Listeria species in bulk tank goat's milk, Journal of Food Protection, 63, 1208-1213 (2000).

Acevedo, D., A. Rodríguez, y A. Fernández, Efecto de las variables de proceso sobre la cinética de acidificación, la viabilidad y la sinéresis del suero costeño colombiano, Información Tecnológica, 21 (2), 2936 (2010).

Ahmad, S., y otros 6 autores, Effects of acidification on physico-chemical characteristics of buffalo milk: a comparison with cow's milk, Food Chemistry, 106 (1), 11-17 (2008). 
Andrade, R., M. Arteaga y M. Simanca, Efecto del salvado de trigo en el comportamiento reológico del yogurt de leche de búfalo, Información Tecnológica, 21(5), 117-124 (2010).

Araya, V. y otros cuatro autores, Evaluación bacteriológica de la leche y queso de cabra distribuidos en el Area Metropolitana de San José, Costa Rica, ALAN, 58(2), 182-186 (2008).

Badui, S., Química de los Alimentos, 4ª̣ edición, pp. 68-180, Longman, México (2006).

Decreto 616, Ministerio de Protección Social (Colombia), Reglamento técnico sobre los requisitos que debe cumplir la leche para consumo humano que se obtenga, procese, envase, transporte, comercialice, expenda, importe o exporte en el país, Bogotá, Colombia (2006).

Duran, M. y otros tres autores, Evaluación higiénico-sanitaria y acción antagónica de cepas de lactobacilos comerciales frente a microorganismos patógenos (Escherichia coli) presentes en el queso de capa del municipio de Mompox, Revista científica, 20(3), 312-317 (2010).

Gianferri, R. y otros cuatro autores, Proton NMR transverse relaxation measurements to study water dynamic states and age-related changes in Mozzarella di Búfalo Campana cheese, Food Chemistry, 105(2), 720-726 (2007a).

Gianferri, R. y otros cuatro autores, A low-resolution and high-resolution nuclear magnetic resonance integrated approach to investigate the physical structure and metabolic profile of Mozzarella di Búfalo Campana cheese, International Dairy Journal, 17(2), 167-176 (2007b).

Gonzáles-Tenorio, R. y otros tres autores, Caracterización de Propiedades Químicas y Fisicoquímicas de Chorizos Comercializados en la Zona Centro de México, Información Tecnológica, 24(2), 3-14 (2013).

Granados, C., G. Urbina y D. Acevedo, Tecnificación, caracterización fisicoquímica y microbiológica del queso de capa de Mompox Colombia, Biotecnol.sector agropecuario y agroindustrial, 8(2), 41-45 (2010).

Granados, C., L.E. Guzmán y D. Acevedo, Análisis proximal, sensorial y de textura de salchichas elaboradas con subproductos de la industria procesadora de atún (Scombridae thunnus), Información Tecnológica, 24(6), 29-34 (2013).

Hleap, J. y A.V. Velasco, Análisis de las propiedades de textura durante el almacenamiento de salchichas elaboradas a partir de Tilapia roja (Oreochromis $s p$.), Revista de la Facultad de Ciencias Agropecuarias, 8(2), 46-56 (2010).

Hussain, I., y otros tres autores, Effects of gelation temperature on Mozzarella-type curd made from buffalo and cows'milk: 2. Curd yield, overall quality and casein fractions, Food Chemistry, 135(3), 1404-1410 (2012).

Maldonado, R. y L. Llanca, Estudio de la calidad del queso de mano comercializado en el estado de Aragua, Venezuela, Revista Científica Universidad del Zulia, 18(4), 431-436 (2008).

Mazzei, P. y A. Piccolo, H HRMAS-NMR metabolomic to assess quality and traceability of mozzarella cheese from Campania buffalo milk, Food Chemistry, 132(3), 1620-1627 (2012).

NTC 399, Instituto Colombiano de Normas Técnicas y Certificación (Colombia), Establece los requisitos y los métodos de ensayo que debe cumplir la leche. Cuarta Actualización, Bogotá, Colombia (2002).

NTC 750, Instituto Colombiano de Normas Técnicas y Certificación (Colombia), Establece los requisitos y los métodos de ensayo que deben los quesos. Tercera Actualización, Bogotá, Colombia (2000).

Romano, R. y otros cuatro autores, Triacylglycerols, fatty acids and conjugated linoleic acids in Italian Mozzarella di Búfalo Campana cheese, Journal of Food Composition and Analysis, 24(2), 244-249 (2011).

Sbodio, O.A. y otros tres autores, Tratamiento Térmico de Leche: Influencia del pH y $\mathrm{CaCl} 2$ en la Elaboración de Queso Cuartirolo, Información Tecnológica, 21(5), 107-116 (2010).

Simanca, M.M., R. Andrade y M.R. Arteaga, Efecto del Salvado de Trigo en las Propiedades Fisicoquímicas y Sensoriales del Yogurt de Leche de Búfalo, Información Tecnológica, 24(1), 79-86 (2013).

Simón, L. y M. Galloso, Presencia y perspectivas de los búfalos en Cuba, Pastos y Forrajes, 34(1), 3-20 (2011).

Zuñiga, L.A., H.J. Fredo, y J.A. Osorio, Estudio de la dureza del queso edam por medio de análisis de perfil de textura y penetrometria por esfera, Revista Facultad Nacional de Agronomía Medellín, 60(1), 3797-3811 (2007). 